\title{
Mapping the city scale anthropogenic heat emissions from buildings in Kuala Lumpur through a top-down and a bottom-up approach
}

\author{
Kai Wang ${ }^{\text {a, }}$, Yasemin D. Aktas ${ }^{\text {a, b }}$, Liora Malki-Epshtein ${ }^{\mathrm{a}}, \mathrm{Di} \mathrm{Wu}^{\mathrm{a}}$, \\ Muhammad Firdaus Ammar Bin Abdullah ${ }^{c}$ \\ ${ }^{a}$ Epicentre Research Group, Department of Civil, Environmental and Geomatic Engineering, University College London (UCL), London, WC1E 6BT, United Kingdom \\ ${ }^{\mathrm{b}}$ UK Centre for Moisture in Buildings (UKCMB), UCL Central House, 14 Upper Woburn Place, London, WC1H ONN, United Kingdom \\ ${ }^{\mathrm{c}}$ Climate and Weather Model Development Section, Malaysian Meteorological Department, Petaling Jaya, Malaysia
}

\section{A R T I C L E I N F O}

\section{Keywords:}

Building energy use

Anthropogenic heat

Urban heating

UHI

Tropical climate

Top-down

Bottom-up

\begin{abstract}
A B S T R A C T
The warming urban climates increase the building energy consumption by changing the heating/cooling loads of the buildings. On the other hand, building induced anthropogenic heat emissions can also contribute to the urban heating, creating a warming feedback loop. Such impact is more profound in the (sub)tropical and hot/arid context, where Air Conditioning (AC) systems are widely used. A better understanding of the building energy consumption and its contribution to urban heating can therefore help mitigate urban heating. To this end, we aim to estimate building energy use and induced heat emissions in Kuala Lumpur, Malaysia, using both a bottom-up strategy based on building energy modelling and a top-down strategy based on national scale energy inventory. We further integrate the building energy model with measured diurnal temperature profiles at different land use areas, to discuss the impact of urban heat island (UHI) on energy use, and potential mitigation strategies through different urban morphologies. The estimated energy use obtained via both bottom-up and the top-down approaches were within the range of actual energy use from case studies available for Kuala Lumpur. It also highlights the need to adapt multi-scale strategies to mitigate the building energy use, and the associated impacts on the UHI.
\end{abstract}

\section{Introduction}

Buildings account for one third of the global energy consumption, and the building induced energy demand is projected to approximately double by 2050 under climate change scenarios (IPCC, 2014). Building energy use is highly responsive to the outdoor climate (Huang et al., 2020). While there is a growing scholarly and governmental interest on building energy efficiency improvements and building induced carbon emissions reductions, these efforts are further challenged by the rapidly changing outdoor thermal environments, due to both climate change, which largely impacts on the energy demand of buildings (Ciancio et al., 2020). Such impact is amplified in the urban area, as an increasing number of people are living in cities, through the phenomena of urban warming. Urban areas are increasingly warmer compared to the surrounding rural areas, known as an urban heat island (UHI) (Oke, Mills, Christen \& Voogt, 2017). The increasing temperatures within urban areas are due mostly to urban morphology, their overall higher-than-rural thermal capacity and the impact of street canyon geometry on radiation and airflow, as well as the associated anthropogenic heat and pollutant emissions.

The warming urban climate impacts on building energy consumption by changing the heating or cooling loads of the buildings (Güneralp et al., 2017). Such urban warming can also exacerbate increasingly frequent heatwaves, and increase the peak electricity demand during these episodes, therefore has implications on energy security (Larcom, She \& van Gevelt, 2019), and the human thermal comfort and health for the areas with limited cooling equipment (Flores-Larsen \& Filippín, 2021). Tropical cities are especially critical in that respect for being both warm and humid. The major energy use in these areas is associated with the cooling demand of the buildings due to the higher temperature throughout the year with more than half of the energy use being associated to space cooling, far more than the other energy such as lighting, ventilation and appliances (Chua, Chou, Yang \& Yan, 2013). This energy use will then turn into waste heat released through AC systems into the atmosphere, and contribute to the increments in the urban temperatures (Huang et al., 2020; Jin, Wang \& Wang, 2020). This high temperature, i.

\footnotetext{
* Corresponding author.

E-mail address: kai.wang@ucl.ac.uk (K. Wang).
} 
e. urban heat island, would further increase the burden of building cooling energy (Sailor, 2013), reduced comfort levels and leading to thermal stress (Aktas et al., 2020) and other health problems (Wong, Alias, Aghamohammadi, Aghazadeh \& Sulaiman, 2017). The increasingly extreme heat events, i.e. heatwaves, are expected to further increase the cooling demand (Morakinyo et al., 2019), thermal discomfort and health risk (Salata et al., 2017). Therefore, the better understanding the interactions between the building energy use and the associated anthropogenic heat with outdoor urban climate is essential in developing policy and technology to mitigate building induced heat emissions and environmental burden, and cooling the cities (Degirmenci, Desouza, Fieuw, Watson \& Yigitcanlar, 2021). An estimation of the waste heat emitted from buildings as a result is extremely important for a correct understanding of the anthropogenic portion of the urban heat island intensity, for an appraisal of thermal comfort and potential heat stress and other threats to health and wellbeing of urban dwellers, and finally, to develop mitigation methods able to address building induced heat emissions.

There are different methods to estimate anthropogenic heat emissions in the urban environment, including inventory approach, energy budget closure approach and building energy models (Sailor, 2011; Yang et al., 2017). Inventory approach is usually based on the energy consumption data, which is constrained by data availability. Moreover, energy consumption data are typically coarse in space and time. As a result, it always relies on geographical data, such as population and nightlight, and empirical diurnal profiles, and top-down to finer spatial and temporal resolutions. This approach has been widely used, from single city (Sailor, Georgescu, Milne \& Hart, 2015) to global scales (Varquez, Kiyomoto \& Kanda, 2021). Energy budget closure approach estimates the anthropogenic heat emissions based on the residual of the surface energy balance of a city or neighbourhood. Though high temporal resolution is applicable in this approach, it highly relies on the assumption of energy balance closure and the measurements or estimations of other energy fluxes, which further challenges its accuracy and practicability (Yu, Hu, Sun, Albertson \& Li, 2021). Building energy modelling can be used to estimate the anthropogenic heat emissions particularly from the building sector through the modelling of detailed energy consumption within buildings. Detailed information at building level, such as building typology, materials, occupants, HVAC system etc., are essential for a more realistic estimate of building energy use and anthropogenic emissions. The building scale modelling can then be bottomed up to larger scales, and the building energy model can also be coupled with urban models (Capel-Timms, Smith, Sun \& Grimmond, 2020).

However, urban and building scale energy data and detailed building information are hard to obtain, as in the case of the Kuala Lumpur city. To better model the interactions between the building cooling demand and outdoor urban climate, this paper aims to estimate the anthropogenic heat emissions from buildings in Kuala Lumpur associated to the energy use for cooling, which can be then integrated in the urban climate modelling systems, such as ADMS-Urban (Wang et al., 2019), or meso-scale models such as WRF (Ooi, Chan, Subramaniam, Morris \& Oozeer, 2017). To this end, we used two different approaches: a bottom-up strategy based on building energy modelling, and a top-down strategy based on national scale energy data. A building anthropogenic heat emission dataset for Kuala Lumpur was then constructed, which will be an essential tool for further building energy and urban climate studies in this region.

\section{Data and methods}

\subsection{Datasets}

\subsubsection{Malaysia national and population energy data}

To estimate the anthropogenic heat emissions from buildings in Kuala Lumpur, the national energy use data were used, as city scale data were not available. The Malaysia Energy Balance reports energy use for three main regions in Malaysia, i.e. Peninsular Malaysia, Sabah and Sarawak, for commercial and residential uses, without detailing it any further based on location. The energy use is highly related to the population data or nightlights (de Miguel, Zamorano, Castaño \& Pascual, 2014), therefore, we used the population data to downscale the energy statistics from national scale to city scale in this study. Table 1 shows the electricity and Liquefied Petroleum Gas (LPG) uses for Peninsular Malaysia (Tenaga, 2015) and Kuala Lumpur, which are estimated based on population ratio between Kuala Lumpur and Peninsula Malaysia $(\sim 1.78 \mathrm{M} / 24.67 \mathrm{M})$.

Note that the energy use consists of electricity and LPG. However, as we could find no information on LPG usage in the literature, only the electricity usage was used for the comparison in Section 3.1. In Section 3.2, both electricity and LPG were considered as the anthropogenic heat emissions from buildings.

\section{2. $3 D$ building data}

\subsubsection{Identification of different building types}

A 3D building model is essential for both bottom-up method to upscale the idealised building model to city scale and for the top-down estimation methods to downscale the whole city to grid. The 3D building dataset for KL city was provided by the UKM's Southeast Asia Disaster Prevention Research Initiative (Seadpri) based on the 2013 LiDAR dataset from the KL City Hall (DBKL). The building dataset consists of the footprint and roof heights for five different classes of structures in Kuala Lumpur: Essential structures, High-rise structures, Non-residential structures, Terrace buildings, and Utilities. As the building energy use data are available only based on commercial- residential differentiation due to the distinct diurnal variations of human activities and energy use in each, we used Google Street View to identity the buildings of the given five types of structures, and re-categorise them as commercial and residential buildings respectively (details are described in section S1 of Supporting Information).

\subsubsection{Estimation the effective building volume}

Then, the total building volume of commercial and residential buildings were calculated as:

$V=\sum_{i} V_{i}=\sum_{i} A_{i} * h_{i}$

where $\mathrm{A}$ is the footprint area, and $\mathrm{h}$ is the roof height, both of which are available from the 3D building dataset; i indicates each building.

A crucial issue was identified while comparing the 3D building model with the street view (Google, 2020): the columnar building model could not fully capture the irregular building shapes, leading to an overestimation of the building volume (section S2 of Supporting Information). Thus, we introduce the effective building volume, $V_{e}$, which describes the total building volume where human activity takes place, and therefore is better indicative of the building energy use and anthropogenic heat.

$V_{e}=\sum_{i} \varepsilon_{i} * f_{o c i} * V_{i}$

Table 1

Energy Data for $2015^{*}$.

\begin{tabular}{lllll}
\hline \multirow{2}{*}{ Energy Type } & \multicolumn{2}{l}{ Peninsular Malaysia (Statistics) } & \multicolumn{2}{l}{ Kuala Lumpur (estimated) } \\
& Commercial & Residential & Commercial & Residential \\
\hline Electricity & $130964.51 \mathrm{TJ}$ & $88533.44 \mathrm{TJ}$ & $9449.79 \mathrm{TJ}$ & $6388.16 \mathrm{TJ}$ \\
LPG & $23430.4 \mathrm{TJ}$ & $25187.68 \mathrm{TJ}$ & $1690.63 \mathrm{TJ}$ & $1817.43 \mathrm{TJ}$ \\
\hline
\end{tabular}

The energy data were provided in GWh (Gigawatt hours) and toe (Tonnes Oil Equivalent), which were then converted to $\mathrm{TJ}\left(10^{12}\right.$ Joule) by the factors of $41.84 \mathrm{TJ} /$ ktoe and 3.6 TJ/GWh respectively. 
where $\varepsilon$ denotes the overestimation factor of the idealised 3D building model, and $f_{o c}$ denotes the occupancy rate of the building, both of which vary for each single building. However, it is impossible to determine $\varepsilon$ and $f_{o c}$ for each building due to the lack of detailed information. For a city scale study, a bulk estimation for $\varepsilon * f_{o c}$ could be made, as $V_{e}$ can also be estimated based on a separate set of parameters relating to the population data at larger scale. In theory, an average area per occupant within a city can be calculated as:

$\lambda=\frac{P}{A}=\frac{P}{V_{e} / h_{s}}$

where $\lambda$ denotes the average area per occupant, $h_{s}$ is the ceiling height which is assumed to be constant in this study $(3 \mathrm{~m})$, and P denotes the population. Then, the effective building volume $V_{e}$ can be calculated as:

$V_{e}=\lambda * h_{s} * P$

Thus, we can estimate the effective building volume ratio $f_{e v}$ from the 3D building model and the population statistics data as shown below:

$f_{e v}=\varepsilon * f_{o c}=\frac{V_{e}}{V}=\frac{\lambda * h_{s} * P}{\sum_{i} A_{i} * h_{i}}$

For residential buildings, the average living space per person in Kuala Lumpur was reported as $18.58 \mathrm{~m}^{2}$ in 1992 (Zhang, 2008). Based on a statistical study on the 100 households in Kuala Lumpur, the average household size is 4.6 people and the floor area is $87 \mathrm{~m}^{2}$ (Murakoshi et al., 2017). In this study, the average value $18.91 \mathrm{~m}^{2}$ per person was used as the average area per occupant $(\lambda)$ of residential buildings. For commercial buildings, we followed on the study by Abd Hamid, Richard and Ramli (2016), who report the average office areas in two commercial buildings (Skywarth and Skymage) as 0.018 and 0.035 person $/ \mathrm{m}^{2}$ : Here we use the average of the two values, 0.026 person $/ \mathrm{m}^{2}$, which is equal to $38.46 \mathrm{~m}^{2}$ per person, as the $\lambda$ of commercial buildings.

In this study, the storey height $h_{s}$ was assumed to be $3 \mathrm{~m}$. The total population of Kuala Lumpur is 1.78 million in 2015, which is estimated based on the adjusted Population and Housing Census of Malaysia 2010 (Department of Statistics, 2010), and the total population in the service sector, which consists the majority of the occupants of commercial buildings, is 1.143 million in 2015 (Department of Statistics, 2018). The total building volume from 3D building dataset is $348,211,909.9 \mathrm{~m}^{3}$ and $589,678,870 \mathrm{~m}^{3}$ for residential and commercial buildings respectively. Thus, based on Eq. (4), the effective building volume ratios $f_{e v}$ were calculated as 0.171 and 0.379 respectively, which will be used to derive the effective building volume values from the 3D building dataset throughout the study. The parameters that were used to calculate $f_{e v}$ are listed in Table 2.

\subsection{Estimation of building energy use}

In this study, both a top-down inventory approach and a bottom-up approach based on building energy modelling were used to capture the city scale building energy use (Fig. 1).

\subsubsection{Top-down approach: inventory method}

To estimate the anthropogenic heat emissions from buildings in Kuala Lumpur, the data regarding the electricity use was used. As the

Table 2

Parameters to calculate effective building volume ratio.

\begin{tabular}{lll}
\hline & Commercial & Residential \\
\hline Total building volume & $348211909.9 \mathrm{~m}^{3}$ & $589,678,870 \mathrm{~m}^{3}$ \\
Average area per occupant & $38.46 \mathrm{~m}^{2}$ per person & $18.91 \mathrm{~m}^{2}$ per person \\
Population & 1.143 million & 1.78 million \\
Ceiling height & $3 \mathrm{~m}$ & $3 \mathrm{~m}$ \\
Effective building volume ratio & 0.379 & 0.171 \\
\hline
\end{tabular}

Malaysia Energy Balance offers energy use data only for three main regions in Malaysia, i.e. Peninsular Malaysia, Sabah and Sarawak (Suruhanjaya Tenaga, 2016), a top-down approach was followed to estimate building energy use. First the city scale energy data $E_{c}$, were estimated from the national energy data, based on the portion of total population of $\mathrm{KL}$ to that in Peninsular Malaysia as discussed in Section 2.1.

$E_{c}=\frac{P_{c}}{P_{N}} E_{N}$

where $E_{N}$ is the amount of national scale energy use, $P_{c}$ and $P_{N}$ are the populations of Kuala Lumpur city and whole of Peninsular Malaysia, respectively.

The Kuala Lumpur energy use, $E_{c}$, was then distributed across the city using the 3D buildings data, which was obtained from Kuala Lumpur City Hall (DBKL). These 3D buildings data were re-categorised to differentiate residential and commercial buildings through a Google Street View survey as explained in Section 2.2.1. The bulk energy data per building volume, $e$, was calculated based on the city scale energy data, $E_{C}$, and the effective building volume, $V_{e}$ :

$e=\frac{E_{C}}{V_{e}}$

Finally, the gridded energy data, $E_{i}$, were estimated as the building volume in each grid, $V_{i}$, multiplied by the effective building volume ratio, $f_{e v}$, and the bulk energy data per building volume, $e$.

$E_{i}=e * f_{e v} * V_{i}$

All the energy use data reported in Table 1 were converted to Joule. The final output unit is $\mathrm{W}^{*} \mathrm{~m}^{-2}$ after the total energy use value divided by time period and area. A conceptual framework of the top-down method is demonstrated in Fig. 1(a).

\subsubsection{Bottom up approach: building energy balance}

(a) Model description

Building energy modelling is widely used to estimate building heat emissions in a certain area based on a building performance simulation supported by data (e.g. building characteristics, internal loads, weather information) to then extend its outcomes to all buildings in the study area with the same constructive features and similar sizes (Zhou, Weng, Gurney, Shuai \& Hu, 2012). In this study, as building scale energy data were not available, the idealised building energy modelling was used to estimate the building energy use. Such estimated building energy data can then be bottom-upped to get the city scale energy use data.

The building indoor heat balance can be described as:

$\rho \mathrm{c}_{\mathrm{p}} \mathrm{V} \frac{\partial \mathrm{T}_{\mathrm{i}}}{\partial \mathrm{t}}=\mathrm{Q}_{\text {meta }}+\mathrm{Q}_{\text {light }}+\mathrm{Q}_{\text {appliance }}+\mathrm{Q}_{\text {rad }}+\mathrm{Q}_{\text {cond }}+\mathrm{Q}_{\text {vent }}$

where $\mathrm{Q}_{\text {meta }}$ is the heat gain due to human metabolism, $\mathrm{Q}_{\text {light }}$ is the heat gain due to lighting, $\mathrm{Q}_{\text {appliance }}$ is the heat gain from appliance.

$\mathrm{Q}_{\mathrm{rad}}$ is the radiation heat gain through windows, and can be calculated as follows:

$\mathrm{Q}_{\mathrm{rad}}=\mathrm{Q}_{0} * \tau * S H G C * A_{\text {window }}$

where $\mathrm{Q}_{0}$ is the solar radiation reaching at the earth surface $\left(\mathrm{W}^{*} \mathrm{~m}^{-2}\right), \tau$ is the transmittance of the window, SHGC is the solar heat gain coefficient, $A_{\text {window }}$ is the window area $\left(\mathrm{m}^{2}\right)$.

$\mathrm{Q}_{\text {wall }}$ is the heat gain through the walls, roofs and windows. It depends on the thermal properties of the building material, the indooroutdoor temperature difference,

$\mathrm{Q}_{\text {cond }}=U_{\text {wall }} *\left(T_{o}-T_{i}\right) * A_{\text {wall }}+U_{\text {window }} *\left(T_{o}-T_{i}\right) * A_{\text {window }}$

where $U_{\text {wall }}$ and $U_{\text {window }}$ are the $\mathrm{U}$ values of the wall and window $\left(\mathrm{W}^{*} \mathrm{~m}^{-2 *} \mathrm{~K}^{-1}\right), T_{o}$ and $T_{i}$ are the outdoor and indoor air temperatures, respectively $\left({ }^{\circ} \mathrm{C}\right)$, and $A_{\text {wall }}$ and $A_{\text {window }}$ is the total surface areas of the 
(a) Top-down approach

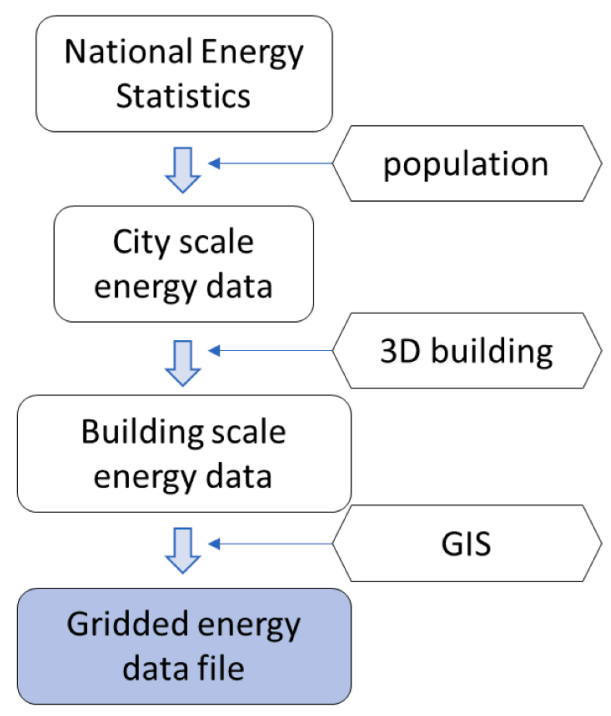

(b) bottom-up approach

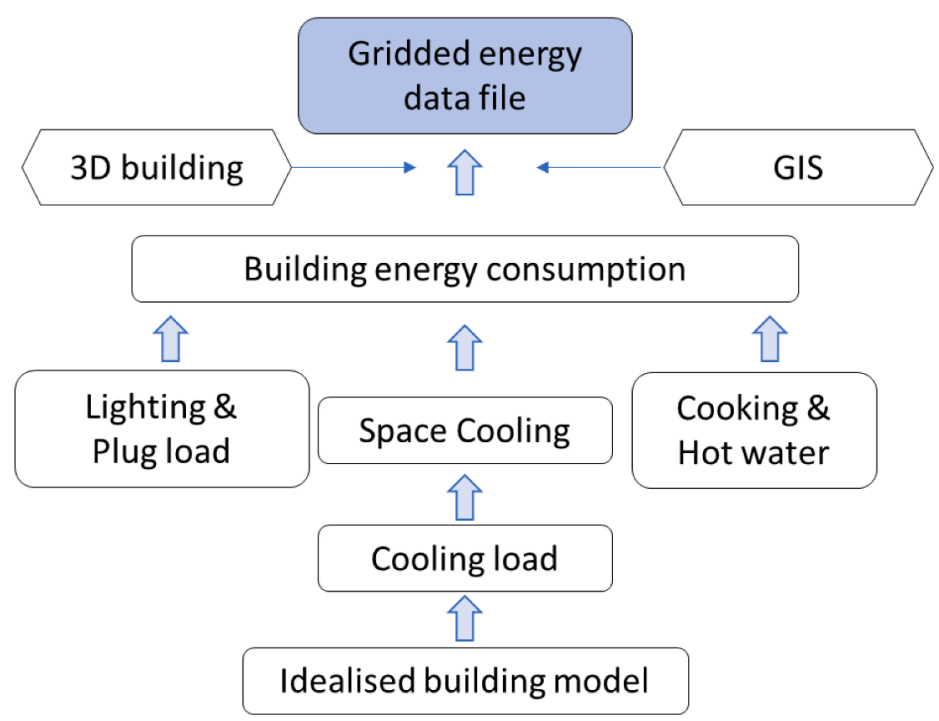

Fig. 1. Illustrations of top-down approach (a) and bottom-up approach (b) used in this study.

wall and window $\left(\mathrm{m}^{2}\right)$. Heat flux through the roof was not considered in this study.

$\mathrm{Q}_{\mathrm{vent}}$ is the heat transfer due to the air change between indoor and outdoor environments. $\mathrm{Q}_{\text {vent }}$ can be generated through natural ventilation and infiltration, and is calculated as follows:

$\mathrm{Q}_{\text {vent }}=\rho \mathrm{c}_{\mathrm{p}} V_{b}\left(T_{o}-T_{i}\right) * A C H$

where $\rho$ is the density of air $(\mathrm{kg} / \mathrm{m} 3), \mathrm{c}_{\mathrm{p}}$ is the specific heat capacity of air $(\mathrm{J} /(\mathrm{K} \mathrm{kg})), V_{b}$ is the building volume $\left(\mathrm{m}^{3}\right), A C H$ is the ventilation or infiltration rate in air change per hour $\left(\mathrm{h}^{-1}\right)$.

This study focuses on overall urban over-heating due to cooling load in the summer, and is not concerned with heating load in the colder months. As this study is conducted in Kuala Lumpur, which is located in the tropics, only space cooling is typically used throughout the year. Thus, building heat balance was established considering cooling load only. First, the quasi-steady building indoor heat balance equation was used to estimate the cooling load $\mathrm{Q}_{\mathrm{CL}}$ of the ideal building in order to calculate the energy use from air conditioning during a certain operation time, $\mathrm{t}$.

$\mathrm{Q}_{\mathrm{CL}}=\sum_{t} \mathrm{Q}_{\text {meta }}+\mathrm{Q}_{\text {light }}+\mathrm{Q}_{\text {appliance }}+\mathrm{Q}_{\mathrm{rad}}+\mathrm{Q}_{\text {cond }}+\mathrm{Q}_{\text {vent }}$

Then, the energy use from lighting \& plug in, cooking \& water heating, together with the air conditioning were summarised up as the building energy use. Therefore, the building energy use per building volume was calculated as follows:

$e=\frac{\mathrm{Q}_{\text {light }}+\mathrm{Q}_{\text {appliance }}+\mathrm{Q}_{\mathrm{CL}} / C O P}{A * h}$

Where $C O P$ is the Coefficient of Performance of air conditioning system, which is used to convert the cooling load into real energy use.

The associated anthropogenic heat emissions per should be the combination of the cooling load and energy use by air conditioning. The former denotes the heat generated by the whole building to be removed to outdoor, the latter denotes the energy that used for the heat removal.

$E=\frac{\frac{\mathrm{Q}_{\mathrm{CL}}}{C O P}+\mathrm{Q}_{\mathrm{CL}}}{A * h}$

Finally, we can upscale the building energy use per building volume and associated anthropogenic heat emissions per building volume to city scale through the 3D building volume data. The framework of the bottom-up method is illustrated in Fig. 1(b).

(b) Parameters

One floor in residential buildings and one floor in commercial buildings were modelled to estimate the cooling loads to calculate energy use by air conditioning in each case to estimate ideal energy use in different types of buildings. An idealised model of residential building was based on the Mirage Residence (Hassan \& Al-Ashwal, 2015). The model was a floor with the size of $28 \mathrm{~m} \times 20 \mathrm{~m} \times 3 \mathrm{~m}$ (height), with 4 apartments and a total of 12 windows with the size $3 \mathrm{~m} \times 1.5 \mathrm{~m}$ (height), and 4 balcony windows with the size $5 \mathrm{~m} \times 3 \mathrm{~m}$ (height). The total area for windows was $114 \mathrm{~m}^{2}$ per floor. Wall area was $174 \mathrm{~m}^{2}$ (wall area=2 $\left.\times(28 \mathrm{~m} \times 3 \mathrm{~m}+20 \mathrm{~m} \times 3 \mathrm{~m})-114 \mathrm{~m}^{2}\right)$. Therefore, the window and wall areas are $28.5 \mathrm{~m}^{2}$ and $43.5 \mathrm{~m}^{2}$ for one apartment respectively. The idealised model of commercial buildings was based on Menara Maxis as measured from the Google Maps street view. The model was a floor with the size of $50 \mathrm{~m} \times 30 \mathrm{~m} \times 3 \mathrm{~m}$ (height), with a row of windows (30), each of which is $3.2 \mathrm{~m} \times 2 \mathrm{~m}$ in size, amounting to a total of $192 \mathrm{~m}^{2}$. Therefore, the wall area was calculated as $288 \mathrm{~m}^{2}$ (wall area $=2 \times(50 \mathrm{~m}$ $\left.\times 3 \mathrm{~m}+30 \mathrm{~m} \times 3 \mathrm{~m})-192 \mathrm{~m}^{2}\right)$. The roof area was calculated as $50 \mathrm{~m} \times 30 \mathrm{~m}=1500 \mathrm{~m}^{2}$.

The number of occupants for the residential buildings is taken as the average household number 4.6, and the occupant number of the commercial buildings is based on the average floor area is $38.46 \mathrm{~m}^{2}$ per person, as proposed by Murakoshi (2017). The working hours are normally 08:00 to 17:00 in Kuala Lumpur, thus all the usages of lighting, appliance, and air conditioning were separated according to office and non-office hours. The light load was set lower due to the availability of daylight. Note that we also consider higher usage of appliance for active periods around the breakfast and dinner hours (06:00-07:00 and 18:00-22:00) in the residential buildings. As the information of appliance usage for residential building was not available, we adopt the light load factors for offices to represent the active hours in residential buildings. The medium design load was used for commercial buildings (Tang, Chin, Guan \& Misara, 2017). The load of appliance during non-active hours was assumed to be $2 \mathrm{~W}^{*} \mathrm{~m}^{-2}$. The parameters used in the building energy model are listed in Table 3 . As the study area is located in the tropics with relatively high solar angle, the direct solar radiation through the windows is much smaller than the diffusive radiation. The Test Reference Year (TRY) data of hourly observed diffusive solar radiation and outdoor air temperature were extracted from Tang 
Table 3

Parameters in idealised building models.

\begin{tabular}{|c|c|c|c|c|}
\hline & Parameter & Residential & Commercial & References \\
\hline \multirow[t]{5}{*}{ Floor/Household dimensions } & Floor Area $\left(\mathrm{m}^{2}\right)$ & 140 & 1500 & Hassan \& Al-Ashwal (2015); \\
\hline & & & & Google Maps Street View 2020 \\
\hline & Ceiling Height (m) & 3 & & \\
\hline & Window Area $\left(\mathrm{m}^{2}\right)$ & 28.5 & 192 & \\
\hline & Wall Area $\left(\mathrm{m}^{2}\right)$ & 43.5 & 288 & \\
\hline \multirow[t]{4}{*}{ Human metabolism } & Occupant Numbers & $5(18: 00-08: 00)$ & $0(18: 00-07: 00)$ & Information in Section 2.1.2 \\
\hline & & $1(08: 00-17: 00)$ & $40(08: 00-17: 00)$ & \\
\hline & Metabolism rate (watt) & 69 for sleeping; & & Quah and Roth (2012) \\
\hline & & 104 for other indoor activities & & \\
\hline \multirow[t]{3}{*}{ Lighting } & Lighting $\left(\mathrm{W}^{*} \mathrm{~m}^{-2}\right)$ & $8(18: 00-22: 00)$ & $0(18: 00-07: 00)$ & Al-Mofleh, Taib, Mujeebu \& Salah (2009) \\
\hline & & $0(23: 00-05: 00)$ & $2(08: 00-17: 00)$ & \\
\hline & & $2(06: 00-17: 00)$ & & \\
\hline \multirow[t]{3}{*}{ Appliance } & Plug $\left(\mathrm{W}^{*} \mathrm{~m}^{-2}\right)$ & $5.4(06: 00-07: 00 ; 18: 00-22: 00)$ & $2(18: 00-07: 00)$ & Tang et al (2017) \\
\hline & & $2(08: 00-18: 00)$ & $10.8(08: 00-17: 00)$ & \\
\hline & & $1(23: 00-05: 00)$ & & \\
\hline \multirow[t]{3}{*}{ Window } & Transmittance & 0.78 & & Double glazed in Hassan and Al-Ashwal (2015) \\
\hline & SHGC & 0.70 & & \\
\hline & $\mathrm{U}$ value $\left(\mathrm{W}^{*} \mathrm{~m}^{-2 *} \mathrm{~K}^{-1}\right)$ & 2.74 & & \\
\hline Wall & $\mathrm{U}$ value $\left(\mathrm{W}^{*} \mathrm{~m}^{-2 *} \mathrm{~K}^{-1}\right)$ & 2.256 & & Yau and Hasbi (2017) \\
\hline \multirow[t]{2}{*}{ Air change } & $\mathrm{ACH}\left(\mathrm{h}^{-1}\right)$ & 0.5 & & Tang et al., 2017 \\
\hline & Operating Temperature $\left({ }^{\circ} \mathrm{C}\right)$ & 25 & & - \\
\hline \multirow[t]{2}{*}{ Air Conditioning } & Operating Hours & 18:00-06:00 & 08:00-17:00 & Hisham, Salim, Hagishima, Yakub and Saipol, 2020 \\
\hline & COP & 4 & & Yau, 2008 \\
\hline
\end{tabular}

et al. (2017).

\subsection{Outdoor climate and diurnal UHI profile}

The energy use is highly responsive to outdoor climate. To quantify the impact of different urban morphologies on the building energy use, near-ground temperature values were monitored in different land use / land cover areas in the city of Kuala Lumpur (for details of this monitoring campaign, please see Aktas et al. 2020). In this study, these monitoring data were used to calculate diurnal profiles of the urban temperatures, which were then combined with input TYR data to use as input for building energy model in Section 2.3.2 to quantify the energy use in different land use scenarios. The diurnal temperature profiles are the averages of the dry month and wet month (Fig. 2a). The urban land use classes considered here included compact high-rise (CHR), compact low-rise (CLR), compact low-rise with timber buildings (CLR-timber), and open low-rise (OLR): all compared with the diurnal temperature profiles obtained from the open low-rise green area (OLG), which was considered to best reflect the rural temperatures, to estimate the diurnal urban heat island intensity (Fig. 2b).
It shows that for the CHR area, there is a daytime cool island, suggesting a significant impact from the shading and heat storage. Due to less heat storage, timber building area shows the largest daytime heat island, but smaller nighttime heat island. The diurnal UHI intensity in the OLR is relative smaller than that in the CHR in both daytime and nighttime, as open streets have better ventilation than more compact urban streets (Yang et al., 2020). These distinct diurnal urban heat island profiles provide us with a good opportunity to study the impact of different urban morphology and building materials on the energy use, so that some urban scale mitigation strategies can be developed.

\section{Results}

\subsection{Estimated building energy use per volume}

We first estimated the bulk energy use per building volume, $e$, using a bottom-up and a top-down estimation strategy to then compare these with the measured data based on the existing literature. The measured electricity demand was used to compare against our modelled data, based on the works of Hassa and Al-Ashwal (2015) for residential
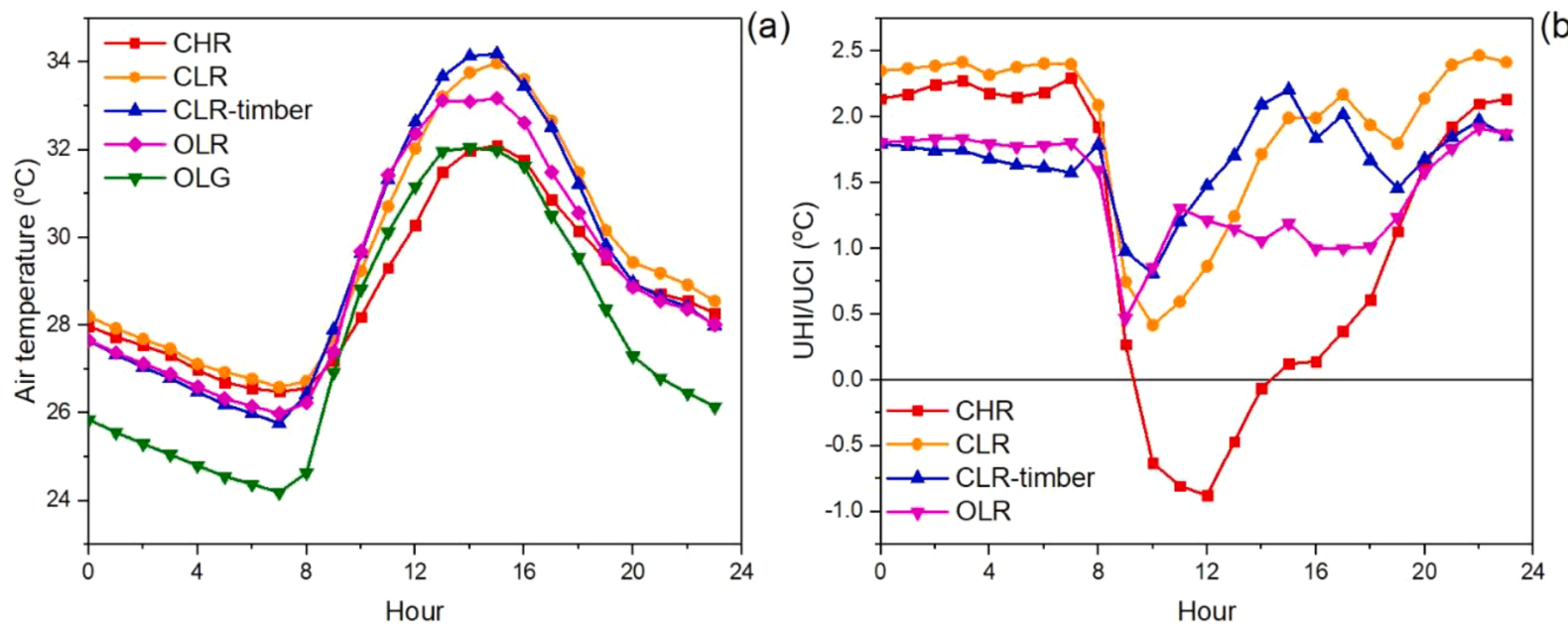

(b)

Fig. 2. (a) Average diurnal temperature profiles in different land use areas; (b) Average diurnal urban heat island intensity profiles of different land use areas by the difference from the open low-rise green (OLG) area. 
buildings, and Abd Hamid et al. (2016) for commercial buildings. For a better comparison, the bulk electricity data per building volume, $e$, as well as the measured energy data were converted to the daily energy use (kwh per $\mathrm{m}^{3}$ per day). The building volume was calculated using the floor area reported in the literature, multiplied by the ceiling height, which is taken as $3 \mathrm{~m}$ for both residential buildings and commercial buildings. The estimated bulk electricity use per building volume, $e$, by the top-down approach was estimated as $0.04 \mathrm{kwh}^{*} \mathrm{~m}^{-3 *} \mathrm{day}^{-1}$ and $0.055 \mathrm{kwh}^{*} \mathrm{~m}^{-3 * \mathrm{day}^{-1}}\left(0.053 \mathrm{kwh} * \mathrm{~m}^{-3 *} \mathrm{day}^{-1}\right.$ and $0.065 \mathrm{kwh} *$ $\mathrm{m}^{-3 *}$ day $^{-1}$ for the combined electricity and LPG) for residential and commercial buildings, respectively, which were slightly lower than the values calculated by the bottom-up approach: $0.059 \mathrm{kwh}^{*} \mathrm{~m}^{-3 *}$ day${ }^{-1}$ and $0.084 \mathrm{kwh}^{*} \mathrm{~m}^{-3 *} \mathrm{day}^{-1}$ respectively. The measured electricity use for residential buildings was $0.043 \mathrm{kwh} * \mathrm{~m}^{-3 *}$ day $^{-1}$ on average for 3 buildings studied by Hassa and Al-Ashwal (2015). The measured electricity use for commercial buildings, on the other hand, was 0.067 $\mathrm{kwh}^{*} \mathrm{~m}^{-3 *} \mathrm{day}^{-1}$ on average for 2 buildings studied by Abd Hamid et al. (2016). The results show the comparable results between the modelled data with the measured data, with relative errors equal to $-6.26 \%$ and $-17.9 \%$ for the top-down approach and $33.6 \%$ and $25.4 \%$ for the bottom-up approach for residential and commercial cases, respectively. Overall, the top-down approach has a slightly better agreement with the measurements reported by the literature (Fig. 3, Table 4).

\subsection{Impact of diurnal urban heat island on the energy use}

The urban heat island induced excessive building energy use were quantified by the building energy model. The changes in the energy use in different land use areas were modelled by the diurnal UHI profiles that calculated in Section 2.4. Generally, the change in the energy use is larger in the residential buildings than in the commercial buildings, as the urban heat island is stronger during nighttime and AC usage is more intense in the residential buildings during night (Fig. 4). For residential buildings, less energy use appeared in CLR-timber area where there is less heat storage and OLR area where there is stronger nocturnal cooling due to larger sky view factor and relatively better ventilation, underlining the importance of less heat storage through building material selection and high sky view factor in reducing the nighttime UHI and energy use. For commercial buildings, what is interesting is that the change of energy use in the CHR is negligible, as this land use area is characterised with a cool island around noon, which can compensate the energy use during early morning and late afternoon hours, highlighting the importance of shading and storage in reducing daytime UHI and energy use. The OLR area also show a relatively small energy use change

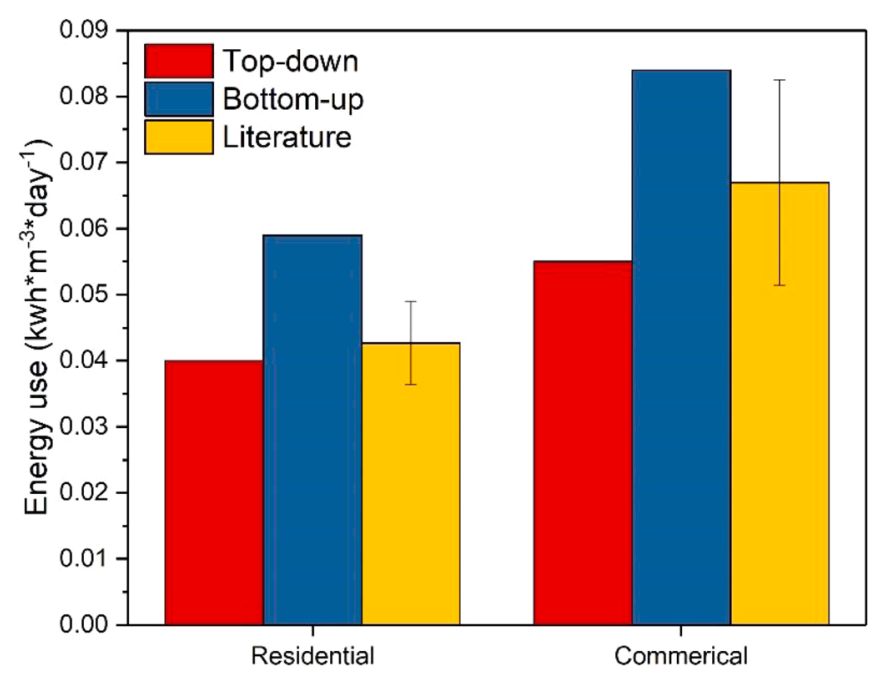

Fig. 3. Comparison between modelled building energy use with the values from literature.
Table 4

Comparison in the modelled daily total building energy use per volume $\left(\mathrm{kwh} * \mathrm{~m}^{-3 *} \mathrm{day}^{-1}\right.$ ) between modelled results with observed results from literatures.

\begin{tabular}{lll}
\hline & Residential $\left(\mathrm{kwh}^{*} \mathrm{~m}^{\left.-3 * \mathrm{day}^{-1}\right)}\right.$ & Commercial $\left(\mathrm{kwh} * \mathrm{~m}^{-3 *} \mathrm{day}^{-1}\right)$ \\
\hline Top-down & 0.04 & 0.055 \\
Bottom-up & 0.059 & 0.084 \\
Literature & $0.043 \pm 0.006$ & $0.067 \pm 0.016$ \\
\hline
\end{tabular}

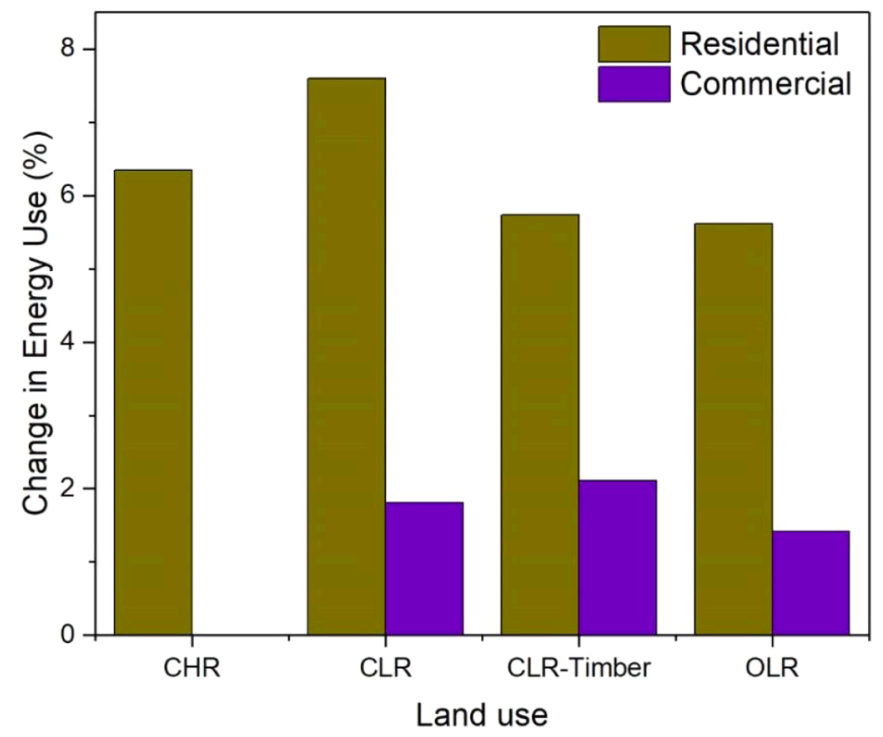

Fig. 4. Change in the expected building energy use due to UHI effects in different land use areas.

suggesting better ventilation can also help reduce the energy use.

\subsection{Gridded anthropogenic heat emissions from buildings}

After estimating the bulk energy use per building volume, the cityscale anthropogenic emissions were estimated using the 3D building volume. As the top-down results being slightly closer to the measured data from the relevant literature, these results were used to produce the gridded hourly average anthropogenic heat emissions: Fig. 5 shows these for the city centre of Kuala Lumpur, with $100 \mathrm{~m}$ resolution (plots for the whole city are shown in the section S3 of Supporting Information). For area with high density buildings, the estimated highest emissions are around $100 \mathrm{~W}^{*} \mathrm{~m}^{2}$, and the highest emission reaches to more than $400 \mathrm{~W}^{*} \mathrm{~m}^{2}$ in the high rise are, which is expected to generate a significant climate forcing to both the local and the regional climate. Higher commercially driven emissions are seen near the city central, as expected, due to the compact and high-rise morphology, while residentially driven emissions are comparatively more evenly scattered across Kuala Lumpur, with some further clustering in/around city centre where the building density is higher (Fig. S3 supporting information).

\section{Discussion}

\subsection{Comparison between top-down and bottom-up methods}

Buildings are responsible for a significant portion of the total energy use, and which is affected by and do contribute to the urban heating in both local and regional scales. In this study, we used top-down and bottom-up approaches to estimate the building scale energy use levels in Kuala Lumpur, which were not previously available in this study area. Results obtained through both approaches were within the range of the actual energy use values from the literature. Our study presents, to the 

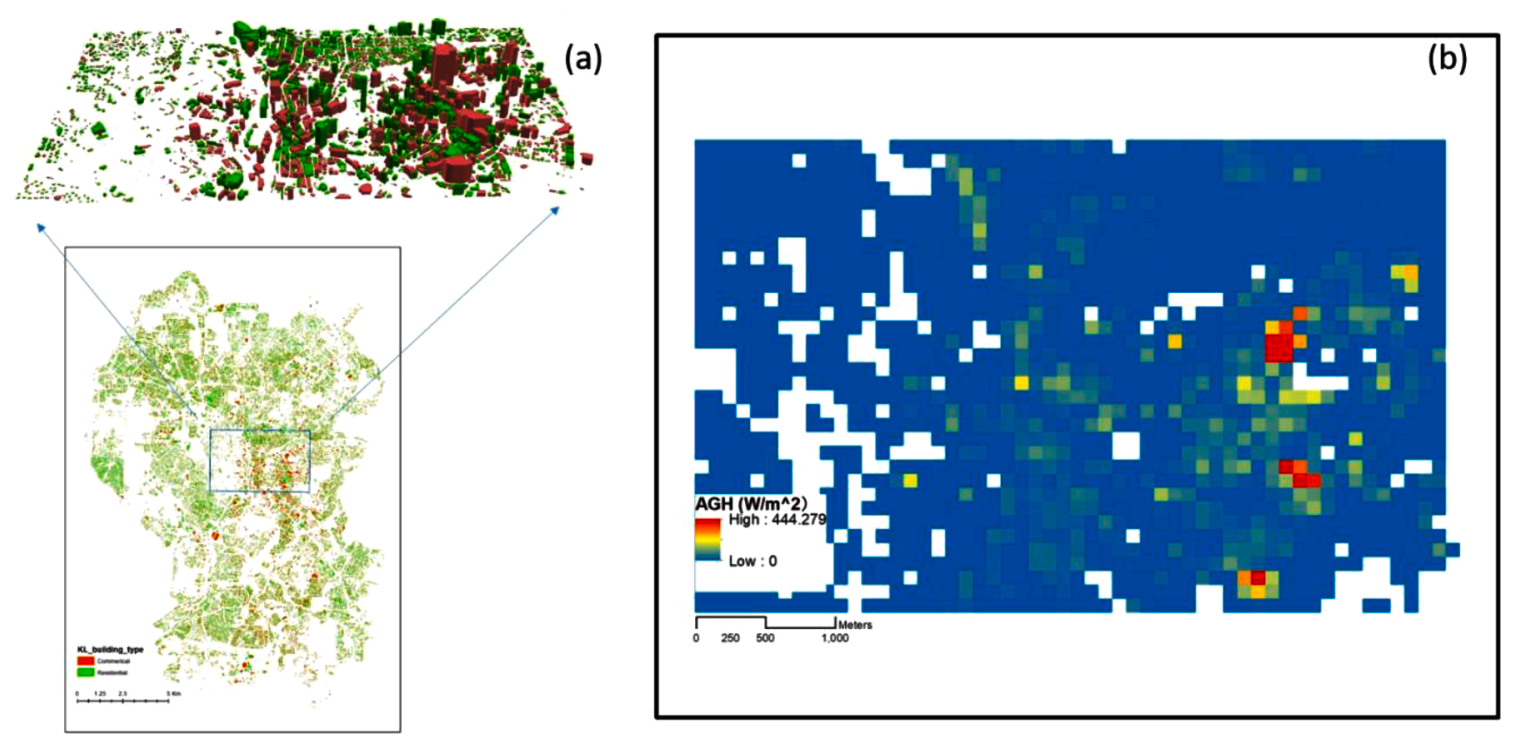

Fig. 5. (a) The building type and 3D building model in the city centre; (b) Estimated average hourly anthropogenic heat emissions ( $\mathrm{W}^{*} \mathrm{~m}^{-2}, 100 \mathrm{~m}$ resolution).

best of our knowledge, the first city scale detailed anthropogenic heat emissions database for Kuala Lumpur.

Though the estimated building energy use data are realistic, there are many assumptions in both modelling approaches which cause uncertainties in the results. Overall, the top-down approach underestimated and the bottom-up overestimated the building energy comparing with the values from the literature. For the top-down approach, the major assumptions were the suitability of a linear correlation between population and energy use while downscaling the national energy data to city scale, and between population and average living space while estimating the effective building volume ratios, although both assumptions led to results in good agreement with the actual energy use from the literature. As Kuala Lumpur is the capital city of Malaysia, the average energy use and living space could be different from the national average, which may result in an underestimation of the top-down approach. The assumptions used in the bottom-up approach, on the other hand, were even more numerous: Firstly, the typical building model that we identified from Google Street View here does not cover different types of buildings, or differentiate apartment blocks and terraced houses within residential building stock, which have different typical area, occupancy rate, ceiling height. Second, the design values for lighting and appliance used in this study may not reflect the actual values, although these parameters are values per area and less sensitive to the total area. Moreover, the thermal properties of the windows and walls may demonstrate differences, affecting the indoor thermal environment under a given outdoor temperature and hence leading to differences in energy use levels. Finally, the AC operation time and operation temperature, is a key component in the building energy modelling, where large differences within the population under examination should be expected and may not have been reflected accurately by our assumptions here. Kubota, Chyee and Ahmad (2009) conducted a survey on the ventilation of Malaysian households and found that air-conditioner ownership level was around $62 \%$ and the air-conditioning was mainly installed in bedrooms. One of the key assumptions in the bottom-up approach is that all the rooms are mechanical ventilated, which should result in an overestimation of energy use. This overestimation may be further exacerbated by the high humidity values in the tropics (Aktas et al., 2020), as the dehumidification processes often cause extra latent cooling load (Shi et al., 2019) and overcooling indoor temperature (Sekhar, 2016), which makes it hard to specify a single operating temperature. These can explain the higher estimates that this approach leads to, despite the fact that it does not account for the urban heat island intensity, while the top-down approach intrinsically does.

Our study shows both ways are capable for the estimation of the city scale anthropogenic heat. Nevertheless, more detailed urban and building scale energy data and building information would further improve the estimations. The top-down method is based on the energy data and agrees well with the actual use. It is suggested that for modelling impact of the anthrophonic heat on outdoor climate, a topdown approach could be adopted as offline input. If a more complicated modelling is aimed to also account for the coupling interaction between indoor energy use and outdoor climate, a building energy model can be used to capture the extra emissions from air conditioning, and more detailed information can further increase the accuracy of the model.

\subsection{Interactions between building energy use and outdoor urban heat}

The highest building induced anthropogenic heat emissions, which appeared in the city centre, are estimated as around $100 \mathrm{~W}^{*} \mathrm{~m}-2$ on an average, and can exceed $400 \mathrm{~W} * \mathrm{~m}-2$ in the densest area at $100 \mathrm{~m}$ resolution. These values are comparable to other tropical cities such as Hong Kong (Cui \& Chui, 2021) and Singapore (Boehme, Berger \& Massier, 2015). Further, this study finds out that the estimated urban heat island intensity (UHII) in different land-use areas in Kuala Lumpur, which varies between 1.5 and $2.5^{\circ} \mathrm{C}$ nighttime and 0.5 and $2{ }^{\circ} \mathrm{C}$ daytime (cool island in compact high-rise areas), is expected to increase the building energy uses by up to $\sim 8 \%$ for residential buildings and $2 \%$ for commercial structures (Fig. 3). These estimated increases in energy use associated to cooling demand are generally in line with levels reported in the relevant literature for tropical locations, e.g. $10 \%$ for Hong Kong for $1.8{ }^{\circ} \mathrm{C}$ UHII (Chan, 2011), and $4.6-12 \%$ for Singapore for $2{ }^{\circ} \mathrm{C}$ UHII (Ignatius, Wong \& Jusuf, 2016).

Our derived anthropogenic dataset can contribute to better urban climate modelling, able to differentiate between the climatic and diverse anthropogenic portions of urban heat island intensity. More attention should be paid to developing means to reduce buildings energy use to limit the associated anthropogenic heat emissions. As for tropical cities where the building energy is highly related to the space cooling, multiscale strategies, ranging from occupant- to building- and urban-scales, should be adapted to reduce the cooling load of the buildings and mitigate the anthropogenic emissions. Better habits (Khan \& Halder, 2015), relative higher thermostat set-point (Kwong, Adam \& Sahari, 2014), better building energy efficiency, performance and conservation (Mirrahimi et al., 2016; Rahman, Rasul \& Khan, 2010; Sadeghifam, 
Zahraee, Meynagh \& Kiani, 2015), integrating natural ventilation (Bastide, Lauret, Garde \& Boyer, 2006) are some of the means to adopt to reduce the energy use, and achieve minimum or zero UHI impact building through heat mitigation strategies on building components (He, 2019).

\subsection{Implications on building design and urban planning}

Besides the aforementioned cooling strategies at occupant and building scales, our modelling results also highlight that different urban design strategies should be adopted based on the different building types and functions, in order to improve the outdoor climate and reduce the urban heating effect, and thus, to reduce the building energy use. Urban and building microclimate cannot be considered separately, and the strategies to reduce building energy use should study both elements. For instance, in tropical climate, shading and increased heat storage are very important in reducing the daytime heat island (high-rise high-density neighbourhoods in high thermal admittance materials such as concrete), while lower heat storage capacity and high sky view factor are key in reducing the nighttime heat island (e.g. open, low-rise areas in lower thermal admittance building materials, such as timber) (Aktas et al., 2020). Thus, for buildings that operate the AC mostly in daytime such as commercial buildings, materials with a higher heat storage capacity and compact urban form to create shading should be encouraged. On the other hand, for buildings that operate the AC mostly during night such as residential buildings, materials with a lower thermal storage capacity and relatively open morphologies should be encouraged. On a building level, other design recommendations would be façade elements with thermal and optic properties dedicated to minimise heat gain (e.g. through glazing, sunshade devices and insulation; see Sun, Gou and Lau 2018), use of other passive design strategies inspired by the tropical vernacular, such as spatial layout and vent systems encouraging natural ventilation, an open, shaded space mimicking a veranda (Zune, Rodrigues \& Gillott, 2020), and integrating energy harvesting means (Zhang et al., 2019). On an urban design level, mitigation methods directed at reducing the UHII including the design of street canyons to encourage in-city ventilation, use of green areas, controlling other anthropogenic contributors such as traffic will be helpful to reduce building energy use and anthropogenic heating.

\section{Conclusions}

In this study, the top-down and the bottom-up approaches were both adopted to estimate the building energy use in the tropical city of Kuala Lumpur. Based on some broad assumptions of linear correlation between population and energy use, as well as between population and average living space, we estimated the building energy use from national statistical data. The calculated electricity data per building volume are 0.04

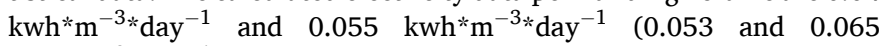
$\mathrm{kwh}^{*} \mathrm{~m}^{-3 *} \mathrm{day}^{-1}$ for the combined electricity and LPG) for residential and commercial buildings, respectively. The bottom-up approach was also conducted based on a building energy model for idealised residential and commercial buildings. The modelled energy data per building volume are $0.059 \mathrm{kwh}^{*} \mathrm{~m}^{-3 *} \mathrm{day}^{-1}$ and $0.084 \mathrm{kwh}^{*} \mathrm{~m}^{-3 * \mathrm{day}^{-1}}$ for residential and commercial buildings respectively. The relative errors between the modelled data and the measured data pulled from the literature are $-6.26 \%$ and $-17.9 \%$ for the top-down approach and $33.6 \%$ and $25.4 \%$ for the bottom-up approach. Both approaches with estimates of building energy use were within the range of actual energy use from case studies available for Kuala Lumpur in the literature, suggesting both approaches are capable to derive such important essential dataset, even if detailed information were not available. Given the recent developments of 3D building mapping (Li, Koks, Taubenböck \& van Vliet, 2020), our approach can also be applied to other cities or larger scale. Meanwhile, localised energy consumption data and building information, especially information about the occupant behaviour and HVAC system, are always essential to its feasibility in other areas or different climate regimes. Our study highlights the feedback loop between urban heating and cooling energy use (up to $8 \%$ of which is estimated to be owed to the UHII), drawing attention to the importance of and need for better climate responsive urban and building design to mitigate the building energy use, and the associated impacts on the UHI, and vice versa. This can include diverse building forms, materials and green infrastructures for residential and commercial building stocks, better building performance, limiting other anthropogenic heating contributors, such as traffic, and so on. Our derived anthropogenic emissions dataset can contribute to better urban climate modelling for the Kuala Lumpur, able to differentiate between the climatic and diverse anthropogenic portions of urban heat island intensity for a more realistic and holistic study of the risks associated with urban heating, and of their mitigation. Future work should concentrate on the quantification of the interactions between building energy use and outdoor urban heating, to detail the amount of savings which can be achieved through different urban design and policy solutions to optimise and focus the efforts for the decarbonisation of built environment.

\section{Declaration of Competing Interest}

The authors declare that they have no known competing financial interests or personal relationships that could have appeared to influence the work reported in this paper.

\section{Acknowledgements}

The authors would like to thank DBKL and SEADPRI's Dr Lim for providing the valuable $3 \mathrm{D}$ building data. We also thank the anonymous reviewers for their very constructive and valuable comments. This study was carried out as part of (a) Newton Ungku Omar Fund administrated by Innovate UK and the Malaysian Industry-Government Group for High Technology (MIGHT) for the EPSRC project entitled "Disaster Resilient Cities: Forecasting Local Level Climate Extremes and Physical Hazards for Kuala Lumpur" (EP/P015506/1); (b) UCL EPSRC Impact Acceleration Award "Modelling Apparent Temperatures in the Tropical City of Kuala Lumpur" (EP/R511638/1).

\section{Supplementary materials}

Supplementary material associated with this article can be found, in the online version, at doi:10.1016/j.scs.2021.103443.

\section{References}

Abd Hamid, M. F., Richard, H. G. A., \& Ramli, N. A. (2016). An analysis on energy consumption of two different commercial buildings in Malaysia. In Proceedings of the IEEE international conference on power and energy (PECon) (pp. 344-349). IEEE.

Aktas, Y. D., Wang, K., Zhou, Y., Othman, M., Stocker, J., Jackson, M., et al. (2020). Outdoor thermal comfort and building energy use potential in different land-use areas in tropical cities: Case of Kuala Lumpur. Atmosphere, 11(6), 652.

Al-Mofleh, A., Taib, S., Mujeebu, M. A., \& Salah, W. (2009). Analysis of sectoral energy conservation in Malaysia. Energy, 34(6), 733-739.

Bastide, A., Lauret, P., Garde, F., \& Boyer, H. (2006). Building energy efficiency and thermal comfort in tropical climates: Presentation of a numerical approach for predicting the percentage of well-ventilated living spaces in buildings using natural ventilation. Energy and Buildings, 38(9), 1093-1103.

Boehme, P., Berger, M., \& Massier, T. (2015). Estimating the building based energy consumption as an anthropogenic contribution to urban heat islands. Sustainable Cities and Society, 19, 373-384.

Capel-Timms, I., Smith, S. T., Sun, T., \& Grimmond, S. (2020). Dynamic anthropogenic activities impacting heat emissions (DASH v1. 0): Development and evaluation. Geoscientific Model Development, 13(10), 4891-4924.

Chan, A. L. S. (2011). Developing a modified typical meteorological year weather file for Hong Kong taking into account the urban heat island effect. Building and Environment, 46(12), 2434-2441.

Chua, K. J., Chou, S. K., Yang, W. M., \& Yan, J. (2013). Achieving better energy-efficient air conditioning-a review of technologies and strategies. Applied Energy, 104, 87-104. 
Ciancio, V., Salata, F., Falasca, S., Curci, G., Golasi, I., \& de Wilde, P. (2020). Energy demands of buildings in the framework of climate change: An investigation across. Europe. Sustainable Cities and Society, 60, Article 102213.

Cui, W., \& Chui, T. F. M. (2021). Measurements and simulations of energy fluxes over a high-rise and compact urban area in Hong Kong. Science of The Total Environment, 765, Article 142718.

de Miguel, A. S., Zamorano, J., Castaño, J. G., \& Pascual, S. (2014). Evolution of the energy consumed by street lighting in Spain estimated with DMSP-OLS data. Journal of Quantitative Spectroscopy and Radiative Transfer, 139, 109-117.

Degirmenci, K., Desouza, K. C., Fieuw, W., Watson, R. T., \& Yigitcanlar, T. (2021). Understanding policy and technology responses in mitigating urban heat islands: A literature review and directions for future research. Sustainable Cities and Society, Article 102873

Department of Statistics (2018). Annual employment survey. Department of Statistics Malaysia, Putrajaya, Malaysia, accessed from https://www.dosm.gov.my/.

Department of Statistics (2010). Population and housing census of Malaysia 2010. Department of Statistics Malaysia, Putrajaya, Malaysia, accessed from https://www. dosm.gov.my/.

Flores-Larsen, S., \& Filippín, C. (2021). Energy efficiency, thermal resilience, and health during extreme heat events in low-income housing in Argentina. Energy and Buildings, 231, Article 110576.

Güneralp, B., Zhou, Y., Ürge-Vorsatz, D., Gupta, M., Yu, S., Patel, P. L., et al. (2017). Global scenarios of urban density and its impacts on building energy use through 2050. Proceedings of the National Academy of Sciences, 114(34), 8945-8950.

Hassan, A. S., \& Al-Ashwal, N. T. (2015). Impact of building envelope modification on energy performance of high-rise apartments in Kuala Lumpur, Malaysia. International Transaction Journal of Engineering, 6, 91-105. Management, Applied Sciences and Technologies.

He, B. J. (2019). Towards the next generation of green building for urban heat island mitigation: Zero UHI impact building. Sustainable Cities and Society, 50, Article 101647.

Hisham, N. A., Salim, S. A. Z. S., Hagishima, A., Yakub, F., \& Saipol, H. F. S. (2020). Statistical analysis of air-conditioning and total load diversity in typical residential buildings. Bulletin of Electrical Engineering and Informatics, 10(1), 1-9.

Huang, J., Jones, P., Zhang, A., Peng, R., Li, X., \& Chan, P. W. (2020). Urban Building Energy and Climate (UrBEC) simulation: Example application and field evaluation in Sai Ying Pun, Hong Kong. Energy and Buildings, 207, Article 109580.

Ignatius, M., Wong, N. H., \& Jusuf, S. K. (2016). The significance of using local predicted temperature for cooling load simulation in the tropics. Energy and Buildings, 118, $57-69$.

IPCC, Change [Edenhofer, O., Pichs-Madruga, R., Sokona, Y., Farahani, E., Kadner, S., K. SeybothAdler, A., Baum, I., Brunner, S., Eickemeier, P., Kriemann, B., Savolainen, J., Schlömer, S., \& von Stechow, C. T. (2014). Zwickel. Cambridge, United Kingdom and New York, NY, USA: Cambridge University Press.

Jin, K., Wang, F., \& Wang, S. (2020). Assessing the spatiotemporal variation in anthropogenic heat and its impact on the surface thermal environment over global land areas. Sustainable Cities and Society, 63, Article 102488.

Khan, I., \& Halder, P. K. (2015). Electrical energy conservation through human behaviour change: Perspective in Bangladesh. International Journal of Renewable Energy Research, 6.

Kubota, T., Chyee, D. T. H., \& Ahmad, S. (2009). The effects of night ventilation technique on indoor thermal environment for residential buildings in hot-humid climate of Malaysia. Energy and buildings, 41(8), 829-839.

Kwong, Q. J., Adam, N. M., \& Sahari, B. B. (2014). Thermal comfort assessment and potential for energy efficiency enhancement in modern tropical buildings: A review. Energy and Buildings, 68, 547-557.

Larcom, S., She, P. W., \& van Gevelt, T. (2019). The UK summer heatwave of 2018 and public concern over energy security. Nature Climate Change, 9(5), 370-373.

Li, M., Koks, E., Taubenböck, H., \& van Vliet, J. (2020). Continental-scale mapping and analysis of 3D building structure. Remote Sensing of Environment, 245, Article 11859.

Mirrahimi, S., Mohamed, M. F., Haw, L. C., Ibrahim, N. L. N., Yusoff, W. F. M., \& Aflaki, A. (2016). The effect of building envelope on the thermal comfort and energy saving for high-rise buildings in hot-humid climate. Renewable and Sustainable Energy Reviews, 53, 1508-1519.

Morakinyo, T. E., Ren, C., Shi, Y., Lau, K. K. L., Tong, H. W., Choy, C. W., et al. (2019), Estimates of the impact of extreme heat events on cooling energy demand in Hong Kong. Renewable Energy, 142, 73-84.

Murakoshi, C. (2017). State of residential energy consumption in Southeast Asia: Need to promote smart appliances because urban household consumption is higher than some developed countries. Eceee Summer Study Proceedings, 1489-1499.

Oke, T. R., Mills, G., Christen, A., \& Voogt, J. A. (2017). Urban climates. Cambridge University Press.
Ooi, M. C. G., Chan, A., Subramaniam, K., Morris, K. I., \& Oozeer, M. Y. (2017). Interaction of urban heating and local winds during the calm intermonsoon seasons in the tropics. Journal of Geophysical Research: Atmospheres, 122(21), 11-499.

Quah, A. K., \& Roth, M. (2012). Diurnal and weekly variation of anthropogenic heat emissions in a tropical city, Singapore. Atmospheric Environment, 46, 92-103.

Rahman, M. M., Rasul, M. G., \& Khan, M. M. K. (2010). Energy conservation measures in an institutional building in sub-tropical climate in Australia. Applied Energy, 87(10), 2994-3004.

Sadeghifam, A. N., Zahraee, S. M., Meynagh, M. M., \& Kiani, I. (2015). Combined use of design of experiment and dynamic building simulation in assessment of energy efficiency in tropical residential buildings. Energy and Buildings, 86, 525-533.

Sailor, D. J., Georgescu, M., Milne, J. M., \& Hart, M. A. (2015). Development of a national anthropogenic heating database with an extrapolation for international cities. Atmospheric Environment, 118, 7-18.

Sailor, D. J. (2011). A review of methods for estimating anthropogenic heat and moisture emissions in the urban environment. International Journal of Climatology, 31, 189-199.

Sailor, D. J. (2013). Energy Buildings and Urban Environment. In Vulnerability of Energy to Climate (Vol. 3, pp. 167-182). Elsevier Inc. https://doi.org/10.1016/B978-0-12384703-4.00321-X.

Salata, F., Golasi, I., Petitti, D., de Lieto Vollaro, E., Coppi, M., \& de Lieto Vollaro, A. (2017). Relating microclimate, human thermal comfort and health during heat waves: An analysis of heat island mitigation strategies through a case study in an urban outdoor environment. Sustainable Cities and Society, 30, 79-96.

Sekhar, S. C. (2016). Thermal comfort in air-conditioned buildings in hot and humid climates-why are we not getting it right? Indoor Air, 26(1), 138-152.

Shi, L., Luo, Z., Matthews, W., Wang, Z., Li, Y., \& Liu, J. (2019). Impacts of urban microclimate on summertime sensible and latent energy demand for cooling in residential buildings of Hong Kong. Energy, 189, Article 116208.

Sun, X., Gou, Z., \& Lau, S. S. Y. (2018). Cost-effectiveness of active and passive design strategies for existing building retrofits in tropical climate: Case study of a zero energy building. Journal of Cleaner Production, 183, 35-45.

Tang, C. K., Chin, N., Guan, Y. T., \& Misara, S. (2017). Building energy efficiency technical guideline for active design (p. 268). Malaysia: Building Sector Energy Efficiency Project (BSEEP). Published by th.

Varquez, A. C. G., Kiyomoto, S., \& Kanda, M. (2021). Global 1-km present and future hourly anthropogenic heat flux. Scientific Data, 8(1), 1-14.

Wang, K., Aktas, Y. D., Stocker, J., Carruthers, D., Hunt, J., \& Malki-Epshtein, L. (2019). Urban heat island modelling of a tropical city: Case of Kuala Lumpur. Geoscience Letters, 6(1), 1-11.

Wong, L. P., Alias, H., Aghamohammadi, N., Aghazadeh, S., \& Sulaiman, N. M. N. (2017). Urban heat island experience, control measures and health impact: A survey among working community in the city of Kuala Lumpur. Sustainable Cities and Society, 35, 660-668.

Yang, W. M., Luan, Y. B., Liu, X. L., Yu, X. Y., Miao, L. J., \& Cui, X. F. (2017). Data descriptor: A new global anthropogenic heat estimation based on high-resolution nighttime light data. Scientific Data. https://doi.org/10.1038/sdata.2017.116

Yang, X., Zhang, Y., Hang, J., Lin, Y., Mattsson, M., Sandberg, M., et al. (2020). Integrated assessment of indoor and outdoor ventilation in street canyons with naturally-ventilated buildings by various ventilation indexes. Building and Environment, 169, Article 106528.

Yau, Y. H. (2008). The use of a double heat pipe heat exchanger system for reducing energy consumption of treating ventilation air in an operating theatre-a full year energy consumption model simulation. Energy and Buildings, 40(5), 917-925.

Yau, Y. H., \& Hasbi, S. (2017). A comprehensive case study of climate change impacts on the cooling load in an air-conditioned office building in Malaysia. Energy Procedia, 143, 295-300.

Yu, Z., Hu, L., Sun, T., Albertson, J., \& Li, Q. (2021). Impact of heat storage on remotesensing based quantification of anthropogenic heat in urban environments. Remote Sensing of Environment, 262, Article 112520.

Zhang, J., Xu, L., Shabunko, V., Tay, S. E. R., Sun, H., Lau, S. S. Y., et al. (2019). Impact of urban block typology on building solar potential and energy use efficiency in tropical high-density city. Applied Energy, 240, 513-533.

Zhang, X. Q. (2008). Housing and urban upgrading in Yantai, China. Housing and urban upgrading in Yantai, China. Nairobi, Kenya: United Nations Human Settlements Programme (UN-HABITAT).

Zhou, Y. Y., Weng, Q. H., Gurney, K. R., Shuai, Y. M., \& Hu, X. F. (2012). Estimation of the relationship between remotely sensed anthropogenic heat discharge and building energy use. ISPRS Journal of Photogrammetry and Remote Sensing, 67, 65-72.

Zune, M., Rodrigues, L., \& Gillott, M. (2020). Vernacular passive design in Myanmar housing for thermal comfort. Sustainable Cities and society, 54, Article 101992.

Suruhanjaya Tenaga (2015). National energy balance 2015. Suruhanjaya Tenaga (Energy Commission), PutraJaya, Malaysia. Accessed from www.meih.st.gov.my. 